\title{
Cognitive Disabilities and the Scope of Contractualist Justice
}

\section{Sophia Isako Wong \\ Long Island University}

John Rawls and other contract theorists have been criticized for excluding people with severe cognitive disabilities from the scope of justice. I argue that this criticism is unfounded. I claim instead it would be irrational for parties to a Rawlsian social contract to exclude the interests of those with severe cognitive disabilities.

Throughout his theory of justice, Rawls assumes "persons are normal and fully cooperating members of society over a complete life, and so have the requisite capacities for assuming that role" (Political 21). He acknowledges "there is the question of what is owed to those who fail to meet this condition, either temporarily (from illness and accident) or permanently" (Political 21). His answer is that he "very much doubts" whether it is possible to answer this question within the scope of justice as fairness. Rawls suggests three alternative responses to the problems on which justice as fairness may fail. One possible response is this: "perhaps we simply lack the ingenuity to see how the extension may proceed" (Political 21). Second, it's possible that "the idea of political justice does not cover everything, nor should we expect it to". Giving this response would imply that the treatment of people with cognitive disabilities is not a matter of justice, but rather a matter of charity or compassion. Third, "the problem may indeed be one of political justice but justice as fairness is not correct in this case, however well it may do for other cases. How deep a fault this is must wait until the case itself can be examined". This last response implies that Rawls's conception of justice as fairness is indeed intended to cover all cases, but turns out to need amendment as it pertains to certain cases. 
Martha Nussbaum investigates this third possibility. She argues that if people with cognitive disabilities aren't considered in choosing the basic principles of justice, then Rawls's theory is incomplete and deeply flawed, and should therefore be rejected in favor of the capabilities account. Nussbaum claims "the case of the mentally disabled proves very revealing for the entire structure of Rawls's contract doctrine, and, more generally, for the project of basing principles of justice on reciprocity between rough equals who are imagined as joining together to reap a mutual benefit" (Capabilities 32). Nussbaum interprets Rawls as "judging that there is no plausible solution to the problem of the mentally disabled that we can extract from his initial bargaining situation" (Capabilities 32).

Indeed, there is textual evidence for the view that questions concerning people with cognitive disabilities are not to be addressed while choosing the principles of justice. In Political Liberalism Rawls states:

Since we begin from the idea of society as a fair system of cooperation, we assume that persons as citizens have all the capacities that enable them to be cooperating members of society. This is done to achieve a clear and uncluttered view of what, for us, is the fundamental question of political justice: namely, what is the most appropriate conception of justice for specifying the terms of social cooperation between citizens regarded as free and equal, and as normal and fully cooperating members of society over a complete life? By taking this as the fundamental question we do not mean to say, of course, that no one ever suffers from illness and accident; such misfortunes are to be expected in the ordinary course of life, and provision for these contingencies must be made. But given our aim, I put aside for the time being these temporary disabilities and also permanent disabilities or mental disorders so severe as to prevent people from being cooperating members of society in the usual sense (Political 20).

Nussbaum interprets Rawls in this passage as postponing all consideration of people with cognitive disabilities to the legislative stage of his theory (Capabilities 16). If Nussbaum's pessimistic reading is correct, then people with cognitive disabilities cannot be considered during the deliberations in the original position (the initial bargain- 
ing situation in which the social contract is negotiated). If at the initial stage the basic principles do not apply to people with cognitive disabilities, then we must invoke some separate set of principles to deal with their interests later, at the legislative stage. Nussbaum finds this strategy unacceptable for a political theory like Rawls' doctrine, which "explicitly aims at completeness and finality."' For a political theory to offer a complete account, she argues, "it is not open to us to say: we have done one part of [the] task [of designing the basic structure of society], but of course other parts, equally basic, based on completely different principles, will come along later" (Nussbaum, Frontiers 139).

I agree with Nussbaum that any theory of justice needs to think about the problem from the beginning, in the design of the most basic level of institutions (Capabilities 26). However, rather than giving up on contractualism, I aim to provide a revised version of RawIsian contract theory that need not be rejected as being incomplete and deeply flawed.

My argument has four parts. Part One, Drawing the Line, responds to Nussbaum's charge that Rawls's theory is flawed because it fails to consider people with cognitive disabilities in choosing the basic principles of justice. I defend a reading of Rawls in which the interests of people with severe cognitive disabilities are represented at the initial stage of choosing the basic principles. In Part Two, Drawing a New Circle, I argue the description of the parties in the original position requires Rawlsians to distinguish between actual cognitive functioning and merely potential cognitive functioning. Thus, it is rational for parties in the original position to choose principles of justice that apply to all moral persons, including those who happen to have merely potential cognitive functioning.

In Part Three, I revise the Rawlsian theory by adding a Principle of Need, which specifies the extent to which the basic structure is required to redress inequalities in access to the conditions that enable individuals to develop their potential for cognitive function-

'See for example $A$ Theory of Justice 135 , where finality is a formal condition on political principles, and 175-8, in the argument for the two principles where it is made clear that the agreement "is final and made in perpetuity" and that "there is no second chance" (176). 
ing. In Part Four, I discuss the main objection to the Principle of Need, that it does not provide a principled basis for limiting our obligations to people with cognitive disabilities. I end by providing a Rawlsian response to this Bottomless Pit Problem.

\section{Part One-Drawing the Line: Minimal Conditions for Equal Justice}

Rawls makes a sharp distinction between variations in moral and intellectual capacities and skills that place people above or below a line as shown in Figure 1. This line represents the threshold at which people have "the minimum essential capacities required to be normal cooperating members of society" (Political, 183). Justice as fairness applies only to free and equal persons, meaning persons who are above this line. What characterizes people above this line? They must possess two moral powers: the capacity for a sense of justice and the capacity for a conception of the good. These two moral powers specify the necessary and sufficient conditions for being counted a full and equal member of society in questions of political justice (Rawls, Liberties 16). The capacity for a sense of justice is

... the capacity to understand, to apply, and to act from the public conception of justice which characterizes the fair terms of cooperation. Given the nature of the political conception as specifying a public basis of justification, a sense of justice also expresses a willingness, if not the desire, to act in relation to others on terms that they also can publicly endorse ... (Rawls, Political 19)

The second moral power, the capacity for a conception of the good, is "the capacity to form, to revise, and rationally to pursue a conception of one's rational advantage or good" (Rawls, Political 19).

Persons (Individuals with BOTH the capacity for a sense of justice and the capacity for a conception of the good)

Non-Persons (Individuals with NEITHER of the above capacities)

Figure 1: The Personhood Line 
When it comes to the two moral powers, there is admittedly much variation among individuals. However, according to the conception of justice as fairness, when the two principles of justice are satisfied, none of the variations among individuals above the line should give rise to injustice. In other words, these variations should not affect the rights and duties (or the benefits and burdens) assigned to individuals. For example, someone very passionate about doing political philosophy that has developed a highly enhanced sense of justice is not therefore entitled to a larger share of the basic liberties. Conversely, someone with a minimal understanding of Rawls's conception of justice is entitled to the same moral consideration as everyone else. What matters is whether someone has the two moral powers; any scalar variations above the line make no difference. Rawls writes, "While individuals presumably have varying capacities for a sense of justice, this fact is not a reason for depriving those with a lesser capacity of the full protection of justice. Once a certain minimum is met, a person is entitled to equal liberty on a par with everyone else" (Justice 443).

The following passage introduces Rawls's idea of a range property. He uses the example of a circle to illustrate his point. The property of being inside a circle is a range property of points in the plane. All points inside this circle have this property, although their coordinates vary within a certain range. Each of these points has this property to an equal extent, since no point inside a circle is more or less inside it than any other interior point (Rawls, Justice 444). Jeremy Waldron discusses the analogous case of state boundaries. He invites us to

... consider the characteristic which a municipality might have of being in New Jersey. . . Though Princeton is in central New Jersey, well away from the state line, and Hoboken just over the river from New York, they are both in New Jersey to the same extent, so far as the law is concerned. One could point to a scalar geographical difference between them; but jurisdictionally it is irrelevant. Being in New Jersey, then, is a range property, ranging over all the points within the boundaries of the state (48-49).

Thus, when it comes to "minimal conditions for moral consideration," Rawls draws the line between those with the capacity for 
a sense of justice and the capacity for a conception of the good on the one hand, and those who completely lack the capacity for moral personality on the other. Note that Rawls distinguishes carefully between a being's capacity, meaning potential, and the realization of that potential.

I have said that the minimal requirements defining moral personality refer to a capacity and not to the realization of it. A being that has this capacity, whether or not it is yet developed, is to receive the full protection of the principles of justice. Since infants and children are thought to have basic rights (normally exercised on their behalf by parents and guardians), this interpretation of the requisite conditions seems necessary to match our considered judgments. Moreover, regarding the potentiality as sufficient accords with the hypothetical nature of the original position, and with the idea that as far as possible the choice of principles should not be influenced by arbitrary contingencies. Therefore it is reasonable to say that those who could take part in the initial agreement, were it not for fortuitous circumstances, are assured equal justice (Justice 445-446).

Rawls imagines the contractors as a small group negotiating on behalf of a wider class of individuals, including those who possess the two moral powers only potentially. He emphasizes "while individuals presumably have varying capacities for a sense of justice, this fact is not a reason for depriving those with a lesser capacity of the full protection of justice" (Justice 443).

Contrary to popular misconceptions, many people initially diagnosed as having "severe" cognitive disabilities have the potential for developing a sense of justice and a conception of the good, given the right circumstances. There are many examples of individuals who have developed moral powers well beyond what was expected of them, thanks to their families' support and advocacy for their inclusion in mainstream education, in the arts, and in politics. Only forty years ago, doctors predicted that infants born with Down syndrome would never learn to walk, talk, or dress themselves. ${ }^{2}$ Because some

${ }^{2} \mathrm{An}$ interesting tale is told by longevity statistics. There are severe racial and socioeconomic disparities in the longevity of people with Down syndrome 
families refused to institutionalize their children, instead choosing to raise them along with their non-disabled siblings, there are many adults with Down syndrome who have become flourishing members of society. Chris Burke became the first actor with Down syndrome to act in a TV series in the United States and has published his autobiography, A Special Kind of Hero. In Count Us In: Growing Up with Down Syndrome, Jason Kingsley discusses completing high school, volunteering for a U.S. Senator and hoping to run for office. According to his web site, Sujeet Desai has a black belt in Tae Kwon Do, plays the clarinet, the piano, and the violin, and married Carrie Bergeron in 2006. The couple now lives together with support from their families and staff. ${ }^{3}$

\section{The "Hard Cases" Objection}

It may appear that I have selectively provided examples of seemingly profound impairments where appropriate conditions allow for development of the moral powers. Although there are many success stories, surely there are also many individuals who reach the higher limits of their potential before acquiring the two moral powers. Admittedly, in certain cases this potential, ordinarily realized in due course, is never actually realized during the lifetime of a given individual. Nussbaum claims that people with severe mental impairments are described in Rawls's theory as "scattered individuals" who, lacking the moral capacities to some essential minimum degree, fail to qualify for equality (Frontiers 65). What I call the Hard

(DS). Whites with DS now live until the average age of 50, but the life expectancy for blacks is 25 and "others" 11 , according to a recent study conducted at the Centers for Disease Control and Prevention. This means that white individuals with DS live twice as long as blacks and four times as long as Asians, Hispanics, and Native Americans with the very same condition. When comparing the life expectancy of whites and blacks in the same socioeconomic class the disparities are not nearly so great, indicating that the causal factors are class and social standing, not the genetic features of racial difference. These statistical variations support the view that a person's longevity, far from being strictly determined by the genetic condition of Down syndrome, is linked to social and economic factors that can be influenced by policy changes.

${ }^{3}$ See Sujeet Desai, Personal Web page at www.sujeet.com; also Claudia Wallis, “A Very Special Wedding," Time Magazine, Sunday, July 16, 2006. 
Cases Objection is that even though Rawls may be able to include individuals labeled mildly or moderately retarded, he cannot include the severely retarded, meaning that group of individuals who are so severely disabled as to be beyond hope of ever developing the two moral powers.

My response to the Hard Cases Objection is as follows. Terms such as "mildly," "severely" or "profoundly" retarded do not refer to natural kinds, but rather to socially constructed categories that are highly unstable, as Licia Carlson has shown in her work. ${ }^{4}$ Determining which individuals are labeled as severely retarded varies depending on historical period, race, and socio-economic status. ${ }^{5}$ Bearing this in mind, we should not let these labels distort our thinking about the individuals in the category and their diverse abilities and capacities. Indeed, the moral capacities demonstrated by any given individual are crucially influenced by the current state of scientific, educational and medical knowledge. For example, some individuals with hearing impairments were thought to be retarded and were denied educational opportunities because they did not communicate successfully with those who diagnosed them. Given the thousands of cases of misdiagnoses so far, scientific knowledge about mental disabilities is highly unreliable.

Furthermore, we must examine the assumptions and methodologies used by those who are attempting to determine the presence or absence of moral capacities. Consider the astonishing progress made by people diagnosed on the autism spectrum as an example. Less than fifteen years ago, Nick Pentzell was initially diagnosed as "profoundly retarded" and was thought to be completely nonverbal. Because his family members continued to search for ways to communicate with him, he learned the technique of facilitated communication at the age of thirteen. He has since written college-level

${ }^{4}$ See Licia Carlson, "Cognitive Ableism and Disability Studies: Feminist Reflections on the History of Mental Retardation". (Hypatia 16:4 (2001): 124-46.) See also Carlson, Mindful Subjects: Classification and Cognitive Disability. Ottawa: National Library of Canada, 1999.

${ }^{5}$ For example, a disproportionate number of black students are labeled "retarded" and placed in classrooms where they receive less attention from teachers, while a disproportionate number of white students are labeled "learning disabled" and given extra tutoring and support for their academic studies. 
papers demonstrating that he certainly possesses the capacities that Rawls describes. ${ }^{6}$ Stories like Pentzell's demonstrate that the label profoundly retarded may lead to neglect and wrongful treatment of individuals who might learn and develop their capacities if they received the necessary care and attention. They also demonstrate that the severity of a person's disability can be socially constructed through the failure to develop technologies such as hearing aids, sign language and facilitated communication. Given my reading of Rawls, all humans with the potential for moral personality, including people believed to have severe cognitive disabilities, do fall within the scope of justice.

\section{Part Two-Drawing a New Circle}

Nussbaum would not be satisfied with this reply, however, because I still have not shown how those who have severe cognitive disabilities could participate in the initial bargaining situation. In Nussbaum's description of social contract theory, the underlying picture is that each of the bargaining parties is "a productive individual who will be willing to sacrifice some prerogatives in order to reap the rewards of mutual cooperation (Frontiers 34).

On Nussbaum's reading, there is presumably no place for infants and children at the bargaining table, according to social contract theorists. Barring the possibility of child labor, how can children be construed as having "normal" productive capacities comparable to those of adults? However, in the passage from Rawls cited above, he does make room for infants and children. He states that those who "could take part in the initial agreement, were it not for fortuitous circumstances, are assured equal justice" (Justice 446).

What is the best way to make sense of Rawls's view here? I propose a second line to be drawn, which distinguishes between those

${ }^{6}$ Nick Pentzell, "I think, therefore I am. I am verbal, therefore I live." Paper presented at the meeting of the Society for Disability Studies on June 15, 2006. See also Jenn Seybert, "Inclusion ... Finally!" (Keynote address to the Maryland Coalition for Inclusive Education, Baltimore, 2002), in Sharing Our Wisdom: A Collection of Presentations by People within the Autism Spectrum, eds. Gail Gillingham and Sandra McClennen (Autism National Committee, 2003). This book is available through the website www.autcom.org. 
who have the unrealized potential to be fully cooperating members of society, and those who are actually exercising their capacities for a sense of justice and a conception of the good. In Figure 2, I've drawn this line as a circle to indicate that it is a range property. The circle is a dotted line rather than a solid line because the border between potential and actual functioning can be crossed in either direction at any time. I define the term actual cognitive functioning as the exercise of one's capacity for a sense of justice and capacity for a conception of the good.

In contrast, the term merely potential cognitive functioning describes those who are outside the circle at a given point in time. This group includes all infants and very young children, as well as adults with the following conditions: severe mental retardation, some psychiatric disorders, some degenerative diseases such as Alzheimer's, and persistent vegetative states.

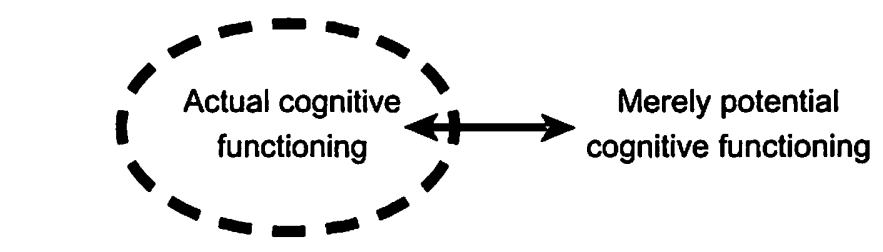

Non-persons (beings lacking the capacity for moral personality)

Figure 2: The Dotted Circle and the Line

Let me make some remarks about the boundary between actual and merely potential cognitive functioning. First, notice that at any given point in time, a person's position relative to the circle is wholly contingent. Over the course of a complete lifetime, the average human being crosses the dotted line at least once, in many cases twice. We are all born outside the circle, with merely potential cognitive functioning. With attentive parenting and access to education, most of us eventually cross the line into the circle at some point during childhood development. The arbitrariness of this crossing becomes evident when we think of the many physical conditions that were historically assumed to place people irrevocably outside the 
circle. ${ }^{7}$ However, largely due to vast improvements in medical technology and educational innovation, several individuals with these conditions have developed actual cognitive functioning and entered into the circle. Many of us, once inside the circle, cross back outside temporarily or permanently due to disease, accident, and ageing. Lastly, there are a few individuals who start outside the circle and never move inside. Although these individuals never actualized their potential, they still belong above the line and are to be distinguished from those who lack the brain stem or other organs necessary for cognitive functioning.

Given these facts about the conditions of human life, I assert two premises, which are represented by the arrows in Figure 2. According to the Vulnerability Premise (the arrow pointing right): Anyone can/could have merely potential cognitive functioning. In other words, it is always possible to cross the line outwards, moving outside of the circle. According to the Developmental Premise (the arrow pointing left): Many can/could develop actual cognitive functioning. In many cases, but perhaps not all, it is possible to cross the line into the circle.

Given both these premises, it is impossible to label particular concrete individuals permanently inside (actual cognitive functioning) or outside (merely potential cognitive functioning). Consider an analogy with income level. The poverty line is an arbitrary line set by policy makers in order to measure economic well-being. The individuals who live below the poverty line cannot be identified by name, because every year some people manage to acquire more income and move above the poverty line, while others lose their jobs and fall below. Any one of us through misfortune, natural disaster, or accident can fall below the poverty line, and it is to be hoped that even for those born into poverty, rising above the poverty line is also possible (although difficult and unlikely) within one lifetime.

${ }^{7}$ Examples include Down syndrome and autism. Note also that in some historical contexts, slaves and women were considered irreparably deficient in cognitive functioning due to biological causes. To the extent that slaves and women were considered non-persons, they were classified as "below the line" in Figure 1, but my point is that they were actually above the line; because they were not given opportunities to demonstrate their cognitive functions, they were placed outside the circle of Figure 2. 
Just as there is no fixed group of people known as "those below the poverty line," there is no particular group of people who fall inside the circle of those who enjoy actual cognitive functioning. In other words, there are no persons who are permanently nondisabled. Any one of us through misfortune, natural disaster, or accident can lose our cognitive functioning in an instant. Similarly, we cannot identify individuals who are perpetually in a state of merely potential cognitive functioning. Acquiring cognitive functioning is a complex and lengthy process that requires resources, attention, and care. ${ }^{8}$

Notice that the circle doesn't divide persons, but rather timeslices of persons. The natural life-cycle of a typical human being starts with time-slices of merely potential functioning, proceeds to time-slices of actual functioning, and may revert to merely potential functioning at any time, particularly near the end of life. If we tried to divide individuals into groups, we'd have to distinguish those who always, sometimes and never have actual cognitive functioning. Unlike the Greek goddess Athena, who sprang fully-grown and armored from the head of Zeus, no human being always has actual cognitive functioning over a complete lifetime. Most of us fall into the category of sometimes, and a very small minority never.

Returning to the "Hard Cases" objection, let us now consider how Rawls's position might account for those who never make the transition from potential cognitive functioning to actual cognitive functioning. It should be noted that strictly speaking, most individuals in persistent vegetative states (PVS) fall into the sometimes category (rather than never), because they had cognitive functioning at earlier stages of life. ${ }^{9}$ Furthermore, misdiagnosis of PVS is not uncommon. One study has reported that $43 \%$ of those patients classified as in a PVS were misdiagnosed and another $33 \%$ were able to recover consciousness while the study was underway (Andrews 13-16). As for

${ }^{8}$ I have written elsewhere about the Enabling Conditions for acquiring moral capacities. See "The Moral Personhood of Individuals Labeled "Mentally Retarded": A Rawlsian Response to Nussbaum," in Social Theory and Practice, forthcoming.

${ }^{9}$ In the US, it is estimated that there may be between $15,000-40,000$ patients who are in a persistent vegetative state, but due to poor nursing home records exact figures are hard to determine. Cf. Joy Hirsch, "Raising consciousness," The Journal of Clinical Investigation, 115(5): 1102, May 2005. 
the small remainder of individuals who never regain consciousness within their lifetimes, this stipulation can only be made once the individual's life has ended. As long as someone is still alive, one can never give the following description: "since going into a PVS, this person never regained the ability to exercise the two moral powers during his or her complete lifetime."

For dealing with individuals in a PVS, there are two approaches for Rawlsians. The first approach is to stipulate that such human beings should lose their claims to moral personhood after some arbitrary period of time in which they fail to demonstrate actual cognitive functioning. This is the approach taken by most hospitals, in which medical treatment is withdrawn from patients who remain unresponsive after thirty days. ${ }^{10}$

The second approach would be to continue to count these individuals as moral persons until the end of their lives, even if they never regain consciousness. This was the approach taken by the family of Michelle Martone, who was almost killed in February 1998 when she was struck by a car while waiting for a bus in front of her dorm. Unconscious, she was moved from rehabilitation program to program, each time being discharged because she did not make sufficient progress during the time allotted. Because her parents persisted in continuing to find treatment for her, Martone began to emerge from the vegetative state seven months after the initial injury. After several months, it was determined she had plateaued and that any more progress was unlikely. In November of 1999, her parents brought her home to live with them, where she continues to receive therapy, has twenty-four hour nursing care, and is making remarkable progress." The advantage of taking the second approach to individuals in PVS is that they sometimes recover long after medical professionals have predicted they are incapable of making any further progress.

So how does this new circle affect the deliberations concerning the principles of justice? For Rawls, the parties in the original position:

${ }^{10}$ See Marilyn Martone, “Decisionmaking Issues in the Rehabilitation Process," The Hastings Center Report vol. 31, 2001.

"According to her blog, Martone is learning to speak and to walk again and has regained most of her long-term memory. See michellemartone.net. 
... know that they are subject to the conditions of human life. Being in the circumstances of justice, they are situated in the world with other men who likewise face limitations of moderate scarcity and competing claims. Human freedom is to be regulated by principles chosen in the light of these natural restrictions. Thus justice as fairness is a theory of human justice and among its premises are the elementary facts about persons and their place in nature. The freedom of pure intelligences not subject to these constraints, and the freedom of God, are outside the scope of the theory (Justice 226).

I argue that natural variation in cognitive functioning is precisely one of these "elementary facts about persons", one of the "conditions of human life." Since Rawls is offering us a theory of justice for humans, then it is highly relevant that human intelligence is affected and constrained by myriad natural contingencies. Thus, the Vulnerability Premise and the Developmental Premise are precisely the kinds of "elementary facts about persons and their place in nature" that parties in the original position should know about and take into consideration.

Therefore I can now articulate my original claim (people with cognitive disabilities fall under the scope of justice) in much more precise terms. I will call this the Inclusive Claim: It would be irrational for self-interested individuals in states of actual cognitive functioning to choose basic principles of justice that exclude individuals in states of merely potential cognitive functioning. If the Inclusive Claim is true, then parties in the original position will know they represent not only healthy competent adults, but also infants and children, as well as others who have merely potential cognitive functioning. Returning to the economic analogy, imagine parties in the original position stipulating there is a certain minimum income that people need in order to be cooperating members of society. Imagine further that the parties recognize that sometimes people fail to obtain that minimum income because of elementary economic facts. Someone then suggests the following basic principle: that whenever one falls below that minimum income level, one is no longer an equal member of society and unable to make claims of justice. It would clearly be irrational for self-interested individuals to choose such a principle of justice, knowing full well they themselves might experience periods of poverty below the minimum income level due to circumstances beyond their control. 
The Inclusive Claim refutes Nussbaum's criticism because it shows that the logic of the bargaining situation does not require the bargainers to think of themselves as always having "normal" productive capacities. Rather, those who currently have actual cognitive functioning negotiate a contract on behalf of themselves in all their possible states and time-slices. Having established who is included in the original position, my next task is to examine how the principles chosen in the original position are applied in Rawls's theory.

\section{Part Three-The Principle of Need}

Recall that in Political Liberalism, Rawls summarizes his conception of "justice as fairness" by stating the two basic principles of justice as follows:

1. Each person has an equal right to a fully adequate scheme of equal basic liberties which is compatible with a similar scheme of liberties for all.

2. Social and economic inequalities are to satisfy two conditions. First, they must be attached to offices and positions open to all under conditions of fair equality of opportunity; and second, they must be to the greatest benefit of the least advantaged members of society (Political 291).

In discussing the first principle of justice, Rawls states:

... the first principle covering the equal basic rights and liberties may easily be preceded by a lexically prior principle requiring that citizens' basic needs be met, at least insofar as their being met is necessary for citizens to understand and to be able fruitfully to exercise those rights and liberties. Certainly any such principle must be assumed in applying the first principle (Political 7).

What are these basic needs? Presumably Rawls is referring to things like adequate food and shelter, which are prerequisites for exercising one's rights and liberties. What is necessary to understand the rights and liberties that are distributed by the first principle? I would argue that actual cognitive functioning is necessary and that it should therefore also count as a basic need. Just as each person has a 
claim to adequate shelter and food, so does each person with potential cognitive functioning have a claim to the resources required to attain actual cognitive functioning. I shall call these resources the "Enabling Conditions" for acquiring actual cognitive functioning. ${ }^{12}$

Let me now formulate a provisional principle following Rawls's proposal. Call it the Principle of Need: the basic structure should provide all citizens with access to the Enabling Conditions necessary for developing the capacities required to understand and exercise the basic rights and liberties. Because it is lexically prior to the first principle, those who design the basic structure must ensure that the Principle of Need is fulfilled before the equal liberties and other benefits of social cooperation are distributed.

Because the Principle of Need must be fulfilled before the First and Second Principles are considered, inequalities in the distribution of food, shelter, and education would be considered graver injustices than other social and economic inequalities such as differences in voting rights, income, or the social bases of self-respect. Thus it becomes clear when we distribute the fruits of social cooperation, it is important to devote resources to helping those with merely potential cognitive functioning approach and attain actual cognitive functioning. This is certainly a compelling claim on behalf of people with severe cognitive disabilities. Without the Principle of Need, it appears that persons who have never achieved cognitive functioning have no claim to the Enabling Conditions. For example, it would be permissible to house non-verbal individuals (who have been labeled as severely retarded) in institutions where they interact only with caregivers who fulfill their basic physical needs, without any opportunities to develop their cognitive abilities. Once

${ }^{12}$ When Rawls construes the two moral powers as potential properties, he is asserting that a given individual will develop a conception of the good and a sense of justice under certain circumstances that may or may not obtain in the future. These specific circumstances are what I call the Enabling Conditions. A dry seed may lie for years in darkness, but then start to germinate under conditions providing moisture, sunlight and nutrients. The Enabling Conditions for the development of a plant are the humidity of the soil, the presence of light, and certain fertilizing nutrients. Similarly, certain human beings may show no signs of having a sense of justice but will gradually develop a sense of justice when they encounter the appropriate Enabling Conditions. 
someone suddenly demonstrates increased cognitive functioning, that individual would be accorded the rights of Rawlsian persons. By contrast, adding the Principle of Need to the theory ensures that all individuals have access to the Enabling Conditions even before they have demonstrated cognitive functioning.

Although the proposal to add the Principle of Need gives rise to some reasonable objections, I have shown elsewhere that this claim can be defended in a way that is consistent with Rawlsian assumptions. ${ }^{13}$ Appealing to the Principle of Need may provide grounds for arguing that PCDs have rights to the Enabling Conditions, and that these rights belong with the other basic rights and liberties that Rawls has outlined. Such an argument would require first showing how Rawls's theory can be interpreted as a rights-based theory, then arguing that the Enabling Conditions are best viewed as rights held by people who have the potential to acquire the two moral powers. Rawlsians would then have to find some way of establishing a ranking among the rights of individuals. This is a position I have defended elsewhere in detail. ${ }^{14}$ For the purposes of the current discussion, however, I will focus on assessing the Principle of Need to see whether it can withstand objections.

\section{Part Four-The "Bottomless Pit" Problem}

The main objection to the Principle of Need is that it does not provide a principled basis for limiting our obligations to people with cognitive disabilities. The Developmental Premise (that people can move from outside to the inside of the circle) holds plausibly enough for "normal" infants and children. But when we consider people with severe cognitive disabilities, the facts suggest many of these individuals will never attain actual cognitive functioning, even if unlimited resources are expended. Does the Principle of Need generate a duty of justice that cannot be fulfilled? In other words,

${ }^{13}$ For example, one of the problems with adding the Principle of Need is that it complicates the determination of the least advantaged group. I discuss these problems further in my dissertation ("Rawlsian Contractualism and Cognitive Disabilities," Columbia University, 2006).

${ }^{14}$ See "Rights for People with Cognitive Disabilities," (currently under review with another journal). 
does it require society to exhaust its resources trying to help people who may never attain actual cognitive functioning? When resources are scarce, it would appear there is no principled way of limiting the demands of the Principle of Need. Reforms of an existing unjust institutional scheme would focus on equalizing access to the Enabling Conditions so people can develop the two moral powers, at the expense of tolerating other kinds of injustices, such as inequalities in voting rights, income, or the social bases of self-respect. I call this the "Bottomless Pit" Problem. And it is troubling indeed, at first glance.

Let me point out that this objection relies crucially on a commitment to two premises. The first is an empirical premise. It concerns the probability of success, where we stipulate that resources have been successfully distributed when an individual crosses the threshold from potential to actual cognitive functioning. The various versions of this premise can be represented by locating them as points along the vertical axis of a graph as shown in Figure 3. The objection relies on the empirical premise that the probability of success is very low. Note that this empirical premise is in turn dependent on an epistemic claim about the facts. One's knowledge of the facts might range from approaching certainty-perhaps based on centuries of scientific studies-to approaching utter uncertainty due to a small sample, an unprecedented case, or general lack of data.

John Stuart Mill famously argued in 1869 that the current state of knowledge about women's potential functioning was inadequate for making epistemic claims, writing: "I consider it a presumption in any one to pretend to decide what women are or are not, can or cannot be, by natural constitution. They have always hitherto been kept, as far as regards spontaneous development, in so unnatural a state, that their nature cannot but have been greatly distorted and disguised" (219). Attempting to assess the potential of women judging from their state in nineteenth-century England (or the potential of people who have spent their early childhoods in institutions with inadequate care) is like measuring the stunted growth of plants kept in restrictive containers, deprived of light and space. As long as the epistemic enabling conditions (allowing spontaneous development) do not obtain, we cannot make any knowledge claims concerning the peculiar tendencies and aptitudes characteristic of women. It 
has been argued elsewhere that our current knowledge about people with cognitive disabilities is similarly lacking. ${ }^{15}$

The second dimension of this problem involves one's basic assumptions about resources. This is represented by the horizontal axis of the graph. Game-theoretic assumptions about resources range from the classic zero-sum view, in which giving to one means taking from another, to the cooperative view, in which many benefit at the same time from the same resources. We make different assumptions along this axis concerning various kinds of resources, depending whether the goods can be divided among many or used by only one person at a time. For example, when it comes to food, giving some to one person necessarily means less for others. The same goes for organ transplants. On the other hand, certain resources can be shared cooperatively. For example, if one person takes music lessons, she can bring others to the lesson so they can learn about music at the same time by listening and observing. The teacher also benefits from the lesson, because she enhances her skill in teaching, and may further use the lesson as an opportunity to train apprentice teachers, who also benefit from observing the lesson.

Looking at the intersection of the two axes, we see that possible applications of the Principle of Need can be roughly divided into four groups, one in each quadrant of the graph. The Bottomless Pit Problem clearly belongs in the lower left-hand quadrant, where we assume 1) the probability of success is very low, hence these cases will create "bottomless pits"; and 2) any amount of resource allocated to one individual reduces the amount available for others to use. These two assumptions characterize the kind of views extensively discussed in the literature on Lifeboat Ethics. These views typically focus on life-or-death scenarios involving scarce resources. Examples include setting priorities in eligibility for organ transplants or dialysis machines, end-of-life issues, and triage in emergency care. Usually the guidelines for distributing resources involve prioritizing the most urgent needs and focusing on the candidates with the best prospects for recovery or success. If the vast majority of people with merely potential cognitive functioning had very poor prospects of

${ }^{15}$ See for example Sophia Isako Wong, "At Home with Down Syndrome and Gender," Hypatia 17:3 (2002), 89-117. 
achieving actual cognitive functioning and most of their needs were for critical health care, then perhaps this model would serve well enough to cover most cases.

However, notice that in many cases, there are high probabilities of success in helping someone achieve actual cognitive functioning. The average infant, for example, usually achieves actual cognitive functioning given attentive parenting and access to basic education. While continuing to assume the zero-sum view of resources, if we change the other assumption and judge that the probability of success is high, then we end up with the model in the upper left-hand quadrant of Figure 3. I call this model Betting on the Underdog because it is characterized by a certain amount of strategic risk-taking. In the case of the typical infant, parents usually assume the resources invested will result in success, and that the investment is worthwhile, sometimes even if paying for better childcare requires financial sacrifices on the part of the whole family.

\section{Assuming High Probability of Success}

"BetTING ON THE UnDERDOG"

- Prospects are promising

- Giving to one takes away from others
"Queening the Pawn"

- Prospects are promising

- Resources benefit many at the same time
Zero-Sum View of Resources

LIFEBOAT ETHICS

- Prospects are poor

- Giving to one takes away from others
Cooperative View of Resources

\section{Assuming Low Probability of Success}

Figure 3: Four Applications of the Principle of Need

I'll briefly describe the remaining two quadrants. Taking the cooperative view of resources, while assuming that the prospects of success are poor gives us what I call the Tending the Garden model, 
in the lower right-hand quadrant. On this model, imagine two pessimistic urban apartment-dwellers who plant tomato seeds in a pot on their north-facing windowsill. They know the probability of success is pretty low, but they still find it worthwhile to spend time and energy tending to the plants, for the intrinsic benefits of gardening. The plants in turn benefit from the resource expended on them. This model may be appropriate for thinking about certain educational settings. It can be argued that creating a learning environment that includes students with cognitive disabilities is beneficial not only to those students, but also to their classmates, teachers and other staff in the school. For example, a building designed with special needs in mind may have clearly marked pathways that reduce stress and confusion, and colorful classrooms that make the visual environment more stimulating for all. The classrooms may include separate areas where students can work on different tasks, and those areas may be used to separate students into small groups throughout the day, not only while students with cognitive disabilities are in the room.

Additionally, there might be moral reasons to treat all individuals on the assumption they have at least some prospect of achieving actual cognitive functioning, even if the statistics suggest that they probably won't do so. I argue that thinking of all persons as potential participants in society is one of the strengths of using a contractualist model. Because contractualism encourages us to think of persons in an idealized way, we come to see everyone as essentially bearers of interests who are united in a system of reciprocal relationships. In order to pass the test of justice as fairness, the basic structure of society should be regulated by principles which would be chosen by contractors representing the interests of all members of society. Of course it is extremely difficult in practice to determine the interests of persons who do not (yet) speak for themselves. However, in assuming that people with cognitive disabilities are on a path toward being able to express themselves, and to advocate for their own interests, theorists and public policy-makers alike are challenged to discover more about these people and what makes their lives go well. In trying to set up structures that encourage people with merely potential cognitive functioning to move beyond non-reciprocal relationships of dependency, for example, we as competent adults are forced to re-examine our own assumptions about the meaning and value of 
reciprocity and independence. Thus, in treating people who have not yet demonstrated cognitive functioning as though they will one day achieve actual functioning, I believe that we offer them the respect and dignity they deserve on a par with all other human beings.

The fourth and final model in the upper right-hand quadrant assumes both that resources can be shared cooperatively, and that the prospects of success are high. Using an analogy from the game of chess, I call this model Queening the Pawn. Initially the pawn is not worth much, but in some cases it is rational to invest one's resources in protecting the pawn's movement across the board. Once it reaches the far side of the board and becomes a queen, that pawn will greatly enhance the resources available to the chess player and support the other pieces. Analogously, notice when people with merely potential cognitive functioning cross the threshold into the realm of actual cognitive functioning, the social rewards can be enormous and well worthwhile. Like "Tending the Garden," this model lends itself particularly well to educational settings.

In summary, this two-dimensional framework provides guidelines for applying the Principle of Need to concrete cases of people with severe cognitive disabilities. I've described the models to give a very rough idea of the kind of thinking that will take place in applying the principle. We may not yet have enough information to decide which of the four models should be used to think about each specific case. I therefore argue that the Rawlsian theory as I have presented it calls for gathering empirical data about which individuals with severe cognitive disabilities are likely to achieve actual cognitive functioning, given what kind of resources.

So far the Bottomless Pit Problem remains: it would be fruitless for the theory to demand that society exhaust its resources in trying to eliminate inequalities in access to the Enabling Conditions for acquiring actual cognitive functioning. In contextualizing the objection, I have contrasted the case of critical health care with basic education. In distributing scarce resources in critical health care, we invoke the zero-sum model, while in basic education we turn to a non-zero-sum, cooperative model of distribution on which society as a whole benefits from resources expended to ensure that everyone's basic needs are met. 


\section{Conclusion}

Let me end by offering a Rawlsian response to the Bottomless Pit Problem. Recall that Rawls opens $A$ Theory of Justice by stating that the first virtue of social institutions is not efficiency, but justice (3-4). Creating a just society may well turn out to be shockingly expensive, but that is beside the point: The rights secured by justice are not subject to the calculus of social interests. Basic structures that distribute resources according to alternative theories may indeed produce higher economic growth rates and more profits for all to share. However, Rawls's goal is to articulate a vision of what justice as fairness requires. He does acknowledge that coordination, efficiency, and stability are fundamental social problems that require some consideration, but these are clearly secondary to his central problem of defining a conception of social justice (Justice 5-6). As Rawls puts it, a conception of social justice provides "a standard whereby the distributive aspects of the basic structure of society are to be assessed... Social arrangements may be efficient or inefficient, liberal or illiberal, and many other things, as well as just or unjust" (Justice 8-9).

Whether a proposed conception of justice is feasible and easily implemented, then, must be assessed separately from its usefulness in showing whether existing societies are unjust, and if so, exactly how these injustices are to be ranked. If a given society does not give people with merely potential cognitive functioning a fair chance to develop actual cognitive functioning (which would enable them to press claims on their own behalf), then that is an injustice that takes precedence over inequalities among people who have already achieved the level of actual functioning that enables them to advocate for their own interests. In the area of income inequality, wealthy members of society (who possess and are exercising the ability to create more income) may well balk at the prospect of distributing the benefits of social cooperation so that the poorest members of society, who are currently deprived, can fulfill all their basic needs. Even if the rich and powerful minority's resistance to change would cause significant political instability, Rawlsians are required to maintain the perspective that the status quo is unjust.

The above Rawlsian response gives us good reason to consider revising the Rawlsian theory by adding the Principle of Need and 
giving it lexical priority over the first two principles of justice. Justice as fairness cannot countenance a basic structure that fails to give members of society the opportunity to develop actual cognitive functioning, which is a necessary condition for enjoying the basic rights and liberties distributed by the first principle of justice. In this way, Rawlsian contractualist justice does indeed include people with cognitive disabilities within its scope. ${ }^{16}$

\section{References}

Andrews, Keith, et al. "Misdiagnosis of the Vegetative State: Retrospective Study in a Rehabilitation Unit." BMJ (July 1996): 13-16.

Burke, Chris. A Special Kind of Hero. New York: Doubleday, 1991. Mill, John Stuart. "The Subjection of Women": The Feminist Papers. Ed. Alice S. Rossi. New York: Columbia University Press, 1973.

Nussbaum, Martha C. "Capabilities and Disabilities: Justice for Mentally Disabled Citizens." Tanner Lectures on Human Values, Salt Lake City: University of Utah Press, 2004: 413-508.

. Frontiers of Justice. Cambridge: Harvard University Press, 2006.

Rawls, John. A Theory of Justice, Ed. John Rawls. Cambridge: Harvard University Press, 1999.

. Political Liberalism. New York: Columbia University Press, 1993.

. The Basic Liberties and Their Priority. Tanner Lectures on Human

Values. Salt Lake City: University of Utah Press, 1982.

Waldron, Jeremy. God, Locke and Equality: Christian Foundations of Locke's Political Thought. Cambridge: Cambridge University Press, 2002.

${ }^{16}$ Many thanks to Peter Montecuollo, Thomas Pogge, Katja Vogt, and two anonymous reviewers for their helpful comments. 